\title{
Functional characterization of the Erwinia chrysanthemi Outs protein, an element of a type II secretion system
}

\author{
Vladimir E. Shevchik and Guy Condemine
}

Laboratoire de Génétique Moléculaire des Microorganismes et des Interactions Cellulaires, CNRS-UMR 5577, INSA Bat 406, 20 Av Albert Einstein, 69621 Villeurbanne, France Author for correspondence: Guy Condemine. Tel: + 33472438088 . Fax: +33472438714.
e-mail: condemin@insa.insa-lyon.fr

\begin{abstract}
Secretion of pectate lyases and a cellulase occurs in Erwinia chrysanthemi through a type II secretion machinery, the Out system. Proper insertion of the secretin OutD in the outer membrane requires the presence of OutS. OutS is an outer-membrane lipoprotein that interacts directly with OutD. Using ligandblotting experiments, it has been shown that this interaction requires at least the 62 C-terminal amino acids of OutD. When this domain was added to the C-terminal extremity of the secreted pectate lyase PelD, the construct was stabilized by OutS but not inserted into the outer membrane. Thus, this domain is sufficient to interact with Outs but it is unable to confer the ability to be inserted into the outer membrane in the presence of OutS. A screen for outs mutants unable to secrete pectate lyases gave only mutants unable to properly localize OutD in the outer membrane and no mutant in the protection function. Thus, the interaction between OutS and OutD can probably not be abolished by the mutation of a single amino acid, and the insertion of OutD in the outer membrane may require additional proteins.
\end{abstract}

Keywords: Gsp protein, secretion, chaperone, lipoprotein

\section{INTRODUCTION}

Translocation of macromolecules across the outer membrane of Gram-negative bacteria can occur by several processes. Some of them require a member of the secretin family of outer-membrane proteins. Secretins are involved in the biogenesis of type IV pili (Drake $\&$ Coomey, 1995), in the secretion of the A-protein of the surface layer of Aeromonas salmonicida (Noonan \& Trust, 1995) and in type III secretion (Genin \& Boucher, 1994). Their role has been extensively studied in two systems: the morphogenesis of the filamentous phages such as $\mathrm{f1}$ and $\mathrm{M} 13$ and the main terminal branch (MTB) of the general secretory pathway (GSP), or type II secretion. The filamentous phage $\mathrm{f} 1$ protein $\mathrm{pIV}$ forms multimers of 14 subunits in the outer membrane, and may form a pore through which the phage could be extruded (Linderoth et al., 1997). The C-terminal half of the protein is necessary for membrane insertion and the $\mathrm{N}$-terminal third forms a periplasmic domain (Russel \& Kasmierczak, 1993; Brissette \& Russel, 1990). The N-

Abbreviations: GSP, general secretory pathway; MTB, main terminal branch.

The accession number for the sequence reported in this paper is $X 65265$. terminal part of the protein is responsible for the specificity of the secreted phage, since a chimeric protein containing the first 149 amino acids of the phage $11 \mathrm{pIV}$ protein exchanged with the same region of the related protein of phage IKe supports $\mathrm{f} 1$ and not IKe assembly (Daeffler et al., 1997b).

The secretins of the MTB of the GSP contain at least two functional domains. The $\mathrm{N}$-terminal part of the various GspD proteins is variable and seems to be located in the periplasm. The Erwinia chrysanthemi GspD protein, OutD, can bind secreted proteins via its $\mathrm{N}$-terminal domain but cannot bind the related proteins of Erwinia carotovora (Shevchik et al., 1997). Thus, the $\mathrm{N}$-terminal part of GspD proteins may be the key to the specificity of type II secretion machineries. The C-terminal part has been proposed as being required for the formation of multimeric structures in the outer membrane (Chen et al., 1996; Hardie et al., 1996a; Shevchik et al., 1997). While the C-terminal half of all secretins is relatively well conserved, their extreme $\mathrm{C}$-terminal end is variable. However, sequence homology can be found between the last 60 amino acids of Klebsiella oxytoca PulD, Er. chrysanthemi OutD and Er. carotovora OutD. This part of the secretin interacts with a small protein (PulS and OutS, respectively) that stabilizes it and helps its 
insertion into the outer membrane (Daefler et al., 1997a; Shevchik et al., 1997). The chaperone and pilotin functions of PulS have been studied by Hardie et al. (1996b). OutS is the only characterized homologue of PulS (d'Enfert \& Pugsley, 1987; Condemine et al., 1992).

We show in this article that OutS is a lipoprotein that interacts directly with the C-terminal end of OutD. Addition of this OutD domain to the end of another protein confers the capacity to be protected by OutS, but not the capacity to be directed to the outer membrane. The lipoprotein acylated N-terminal part of OutS is necessary for its pilotin function, but not for the protector effect with regard to OutD.

\section{METHODS}

Bacterial strains, plasmids and culture conditions. The bacterial strains and plasmids used in this study are listed in Table 1. Er. chrysanthemi and Escherichia coli cells were grown at $30^{\circ} \mathrm{C}$ and $37^{\circ} \mathrm{C}$, respectively, in LB medium or M63 minimal medium (Miller, 1972) supplemented with a carbon source $(0.2 \%)$ (except polygalacturonate, $0.4 \%$ ) and, when required, antibiotics at the following concentrations : $100 \mu \mathrm{g}$ ampicillin $\mathrm{ml}^{-1}, 50 \mu \mathrm{g}$ kanamycin $\mathrm{ml}^{-1}, 20 \mu \mathrm{g}$ chloramphenicol $\mathrm{ml}^{-1}$.

Recombinant DNA techniques and generation of constructs. Standard recombinant DNA procedures were performed essentially as described by Sambrook et al. (1989). DNA sequences were determined by the chain termination method with T7 DNA polymerase (Pharmacia).

To construct the periplasmic OutS derivative, a SacI-XboI fragment from $\mathrm{pBA} 3$ containing out $S$ was cloned between the Sacl and Xhol sites of pET20. The outS signal sequence was deleted and the out $S$ coding sequence was put in-frame with the pelB signal sequence (PelB ${ }^{\mathrm{sp}}$ ) of pET20, after digestion of the plasmid with SgrAI and EcoRV and treatment with the Klenow enzyme. The pelB ${ }^{\text {sp }}$-out $S$ construct was then digested with $B g l I I$ and $X h o l$, and introduced into the expression vector pACT3, digested with BamHI and Sall. To create the PelD-'62D hybrid protein, the C-terminal 12 amino acids of PelD were replaced with the C-terminal 62 amino acids of OutD, using a 4-amino-acid junction of the pUC118 polylinker (an Xbal-Smal fragment). A MamI-NheI fragment, from pN715 containing pelD, was cloned into the EbeI and XbaI sites of pUC118. A PvuII-Smal fragment from this plasmid was cloned into the EcoRV and NruI sites of the pTdB-OD, to give an in-frame pelD'-'outD fusion.

Hydroxylamine mutagenesis. This was performed as described by Yang et al. (1993). Forty microlitres of hydroxyla mine chlorhydrate, $\mathrm{pH} 6.0$, was added to $5 \mu \mathrm{g}$ plasmid DNA in $60 \mu \mathrm{l} 100 \mathrm{mM}$ phosphate buffer, $\mathrm{pH} \mathrm{6.0.} \mathrm{The} \mathrm{mixture} \mathrm{was}$ incubated at $75^{\circ} \mathrm{C}$ for $90 \mathrm{~min}$, dialysed against water and the DNA was recovered by ethanol precipitation. The outS mutant strain A1903 was transformed by electroporation with the mutagenized plasmids. The ability of transformants to secrete pectate lyases was tested on polygalacturonate + glycerol plates (Hugouvieux-Cotte-Pattat et al., 1992). The plasmid was extracted from each non-secreting transformant and purified in E. coli.

Enzyme assays. Pectate lyase activity was assayed on the supernatant or on the toluenized cell fraction as described by Moran et al. (1968). $\beta$-Galactosidase activity was determined by following the degradation of $o$-nitrophenyl- $\beta$ - $D$ galactoside into $o$-nitrophenol, measured at $420 \mathrm{~nm}$ (Miller, 1972).

Isolation and analysis of cell fractions. Exponentially grown cultures $\left(\mathrm{OD}_{600} 0.8-1.0\right)$ were usually used for the cell fractionation. Release of periplasmic proteins was performed by osmotic shock, and cell membrane fractionation was performed by sucrose gradient centrifugation, as described previously (Shevchik et al., 1996). Crude membrane fractions were isolated by centrifugation $(200000 \mathrm{~g}$ for $2 \mathrm{~h})$ after Frenchpress disintegration of cells and redissolved in $50 \mathrm{mM}$ Tris $/ \mathrm{HCl}, \mathrm{pH} 8 \cdot 0$. Gel-filtration chromatography of the periplasmic proteins was performed using a Superose $12 \mathrm{HR}$ 10/30 (Pharmacia) column pre-equilibrated with $50 \mathrm{mM}$ Tris $/ \mathrm{HCl}, \mathrm{pH} 8.0,150 \mathrm{mM} \mathrm{NaCl}$. The periplasmic fraction $(0.3 \mathrm{ml})$ adjusted with this buffer was applied to the column and eluted with the same buffer. Fractions of $0.2 \mathrm{ml}$ were collected, analysed for $A_{280}$ and proteins were precipitated with 5 vols ethanol. Protein patterns were analysed by SDSPAGE followed by immunoblotting with anti-OutD and antiOutS antibodies. The column was calibrated with the following molecular mass standards : $\alpha_{2}$-macroglobulin $(340 \mathrm{kDa}$ and $170 \mathrm{kDa}$ - non-reduced and reduced forms, respectively), fructose-6-phosphate kinase $(85 \mathrm{kDa})$, BSA $(67 \mathrm{kDa})$, chymotrypsinogen A $(25 \mathrm{kDa})$ and RNase $A(13.7 \mathrm{kDa})$.

Protein labelling. Overexpression and exclusive labelling of plasmid-encoded proteins was carried out using the T7 promoter/T7 polymerase system of Tabor \& Richardson (1985). Labelling was performed with $\left[{ }^{35} \mathrm{~S}\right]$ methionine and $\left[{ }^{35} \mathrm{~S}\right]$ cysteine (Promix, Amersham) or $\left[{ }^{3} \mathrm{H}\right]$ palmitate (Amersham). For the ligand-blotting experiments, ${ }^{35} \mathrm{~S}$-labelled OutS was extracted from cells with Triton X-100. Exclusive labelling was performed over a period of $20 \mathrm{~min}$, then cells were washed in $20 \mathrm{mM}$ Tris $/ \mathrm{HCl}, \mathrm{pH} 8.0$, and incubated in $1 \%(\mathrm{v} / \mathrm{v})$ Triton $\mathrm{X}-100,20 \mathrm{mM}$ Tris $/ \mathrm{HCl}, \mathrm{pH} 8 \cdot 0$, for $30 \mathrm{~min}$. The cells were removed by centrifugation and the amount of labelled OutS in the supernatant was estimated by SDS-PAGE.

Gel electrophoresis, immunoblotting and ligand blotting. SDS-PAGE was usually performed according to Laemmli (1970). Concentrations of acrylamide and bisacrylamide varied from 8 to $15 \%(\mathrm{w} / \mathrm{v})$ and from 0.2 to $0.4 \%$ respectively, depending on the experiment. Proteins were transferred onto nitrocellulose in a semi-dry apparatus, and the membrane was incubated with antibodies and developed with the ECL detection kit (Amersham), as described previously (Shevchik et al., 1997). The primary antibodies used were anti-PelD diluted 1:5000, anti-MBP diluted 1:10000 (Biolabs), antiOutS diluted 1:6000, anti-PulS diluted 1:5000 (provided by A. Pugsley, Institut Pasteur, Paris, France) and anti-OutD diluted $1: 3000$.

For the ligand-blotting experiments, the crude membrane fractions containing OutD or its derivatives were boiled for $3 \mathrm{~min}$ in the Laemmli buffer, separated by SDS-PAGE and blotted onto nitrocellulose. The membrane was saturated with $3 \%(w / v)$ BSA, incubated for $1 \mathrm{~h}$ with labelled OutS, washed three times for $10 \mathrm{~min}$, dried and exposed to film. The incubations were usually performed at room temperature with

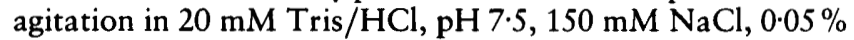
Tween 20.

Preparation of OutS antiserum. PelB ${ }^{\text {sp }}$-OutS was overproduced in E. coli NM522 containing pACTS1. Cells from $100 \mathrm{ml}$ culture were pelleted and the periplasmic proteins were extracted by the freezing-thawing method of Johnson \& Hecht (1994). The supernatant was loaded onto an $18 \%$ preparative SDS-PAGE gel. The band containing PelB ${ }^{\text {sp }}$-OutS 
Table 1. Bacterial strains and plasmids used in this study

\begin{tabular}{|c|c|c|}
\hline Strain/plasmid & Genotype/description & Reference/origin \\
\hline \multicolumn{3}{|l|}{ Er. chrysanthemi } \\
\hline A350 & $\operatorname{lm} r T^{\mathrm{c}} \operatorname{lac} Z$ & Laboratory collection \\
\hline A837 & $\operatorname{lm} r T^{\mathrm{c}} \operatorname{lac} Z k d g R$ & Laboratory collection \\
\hline A1903 & $\operatorname{lm} r T^{\mathrm{c}}$ lacZ outS: : uid A-kan & Condemine et al. (1992) \\
\hline \multicolumn{3}{|l|}{ E. coli } \\
\hline K38 & $\mathrm{HfrC}(\lambda)$ phoA4 pit-10 tonA22 ompF627 relA1 & Russel \& Model (1984) \\
\hline BL21 & $\begin{array}{l}F^{-} d c m \text { omp } T \text { bsdS gal, } T 7 \text { polymerase gene under the } \\
\text { lacUV5 promoter }\end{array}$ & Tabor \& Richardson (1985) \\
\hline MC3 & $p s p A-l a c Z$ & Bergler et al. (1994) \\
\hline NM522 & $\begin{array}{l}\text { supE thi-1 } \Delta\left(\text { lac-proAB) } \Delta(m c r B-h s d S M) 5 \mathrm{r}_{\mathrm{k}}^{-} \mathrm{m}_{\mathrm{k}}^{-} \mathrm{F}^{\prime}\right. \\
\text { proAB lacl } l^{\mathrm{a}} \Delta \text { lacZM15 }\end{array}$ & Stratagene \\
\hline \multicolumn{3}{|l|}{ Plasmids } \\
\hline pET20 & $\mathrm{Ap}^{r}$ & Novagen \\
\hline рACT3 & $\mathrm{Cm}^{\mathrm{r}}$ & Dykxhoorn et al. (1996) \\
\hline pT7-5 & $A p^{r}$ & Tabor \& Richardson (1985) \\
\hline pT7-6 & $A p^{r}$ & Tabor \& Richardson (1985) \\
\hline pUC118 & $\mathrm{Ap}^{r}$ & Sambrook et al. (1989) \\
\hline pGP1-2 & $c 1857, \mathrm{~T} 7$ polymerase gene under the $\lambda \mathrm{P}_{\mathrm{L}}$ promoter $; \mathrm{Km}^{\mathrm{r}}$ & Tabor \& Richardson (1985) \\
\hline pACTS1 & pACT3 containing pel $B^{\text {sp }}-o u t S$ & This work \\
\hline pBA3 & pBluescript containing $B c l$ I-AatII fragment carrying outS & This work \\
\hline pBA3-37 & As pBA3 with outS L37F & This work \\
\hline pBA3-110 & As pBA3 with outS R110C & This work \\
\hline pCHAP378 & pBR322 carrying puls & d'Enfert \& Pugsley (1987) \\
\hline pVLTS & pVLT31 carrying outS & Shevchik et al. (1997) \\
\hline pACOS & pACYC184 carrying outS & Shevchik et al. (1997) \\
\hline pT7OS & pT7-5 carrying out $S$ & This work \\
\hline pACOD & pACYC184 carrying outD & Shevchik et al. (1997) \\
\hline pTdB-OD & pT7-6 carrying outD & Shevchik et al. (1997) \\
\hline pTdB-ODC1 & pT7-6 carrying outD $\Delta 648-710$ & Shevchik et al. (1997) \\
\hline pTdB-ODC2 & pT7-6 carrying outD $\Delta 382-710$ & Shevchik et al. (1997) \\
\hline pODN1 & pBluescript carrying outD $\Delta 66-116$ & Shevchik et al. (1997) \\
\hline pODN & pBluescript carrying outD $\Delta 1-285$ & Shevchik et al. (1997) \\
\hline pODN2 & pET20 carrying pel $B^{\text {sp }}-$ outD $\Delta 1-285$ & Shevchik et al. (1997) \\
\hline pMMB-OD & pMMB207 (de Lorenzo et al., 1993) carrying outD, $\mathrm{Cm}^{\mathrm{R}}$ & This work \\
\hline $\mathrm{pN} 715$ & pBR322 containing pelD & $\begin{array}{l}\text { Hugouvieux-Cotte-Pattat } \\
\text { et al. (1992) }\end{array}$ \\
\hline pTPLD-'62D & pT7-6 carrying pelD'-'outD fusion & This work \\
\hline
\end{tabular}

was cut out and the protein was extracted with three washes with $10 \mathrm{mM}$ Tris/ $\mathrm{HCl}, \mathrm{pH} 8 \cdot 0,0 \cdot 1 \%$ SDS. The protein was concentrated with Centricon 3 and injected into a rabbit. Serum was used with no purification at the dilutions indicated.

\section{RESULTS}

\section{OutS is an outer-membrane lipoprotein}

Re-examination of the previously published outS sequence (X65265; Condemine et al., 1992) showed that a $\mathrm{C}$ residue had been omitted at position 365 . The resulting frameshift led to the identification of an erroneous start codon. In the corrected sequence, the out S ORF begins with an ATG codon located at nucleotide 272, which is preceded by a Shine-Dalgarno sequence (AAGA) at nucleotides 255-258 (data not shown). This ORF encodes a putative protein of 133 amino acids with a deduced molecular mass of $14336 \mathrm{Da}$. The $20 \mathrm{~N}$ terminal amino acids of OutS show the characteristics of a lipoprotein signal sequence, with the cleavage site of the lipoprotein signal peptidase (LAAC) (Fig. 1). Thus, OutS could be processed and fatty-acylated on the Nterminal cysteine. To confirm this hypothesis, out $S$ was placed under the control of the T7 promoter in pT7-5 (to give $\mathrm{pT} 7 \mathrm{OS}$ ). When the proteins encoded by the plasmid were exclusively labelled with $\left[{ }^{35} \mathrm{~S}\right]$ methionine, a $12 \mathrm{kDa}$ product was detected. When the labelling was performed with $\left[{ }^{3} \mathrm{H}\right]$ palmitate, a protein of the same size was detected (Fig. 2). This confirmed that the $12 \mathrm{kDa}$ protein is the processed form of the lipoprotein OutS. Fractionation of the membranes of Er. chrysanthemi and an E. coli strain producing OutS, by flotation on a sucrose 
OutS MHVSSLKVVLFGVCCLSLAACQTPAPVKNTASRSAASVPANEQISQLASLVAASKYLRVQCERSDLPDDGTILKTAV PUIS MFRFILFPMNAVVLLSGC----QQNRPTTLSPAVSGQAQLEQLASVAAGARYLKNKCNRSDLPADEAINRAAI

\section{V60}

$\begin{array}{ccc}\text { T60 } & \text { N77 } & \text { C110 } \\ \text { OutS } & 78 & \text { NVAVQKGWDTGRYQSLPQL8ENLYQGLLKDGTPKATQCSSFNRTMTPFLDAMRTVR }\end{array}$

OutS 78 NVAVQKGWDTGRYQSLPQL8ENL YQGLLKDGTPKATQCSSFNRTMTPFLDAMRTVR
PulS 70 NVGKKRGWANIDANLLSQRBAQLQQLQQDSTPEATKCSQFNRQLAPFIDSLRNK
Fig. 1. Alignment of the sequences of OutS and PulS. The Puls sequence is from d'Enfert \& Pugsley (1987). The position of the lipoprotein signal peptidase cleavage site is indicated by a black arrowhead. Identical amino acids are indicated by asterisks. The amino acids changed by the hydroxylamine mutagenesis are shown in bold. The numbering is that of the mature protein. (a)

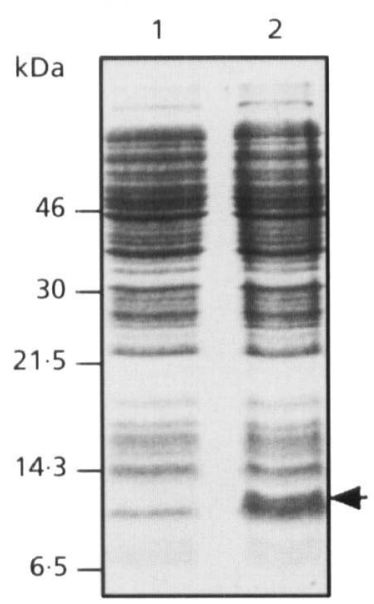

(b)

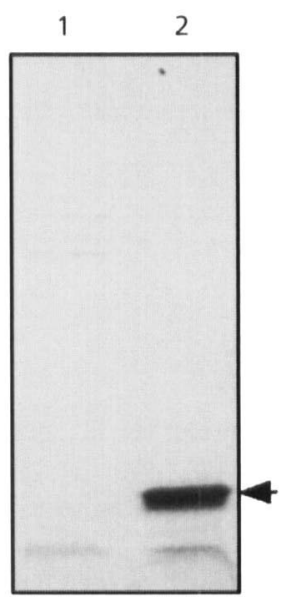

(c)

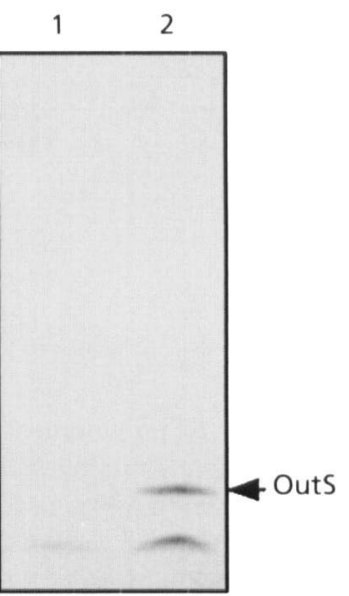

Fig. 2. Exclusive expression of outS in the T7 RNA polymerase system. T7 RNA polymerase synthesis was induced in $E$. coli K38/pGP1-2/pT7-6 (OutS-) (lane1) and K38/pGP1-2/pT7OS (OutS ${ }^{+}$(lane 2) cells. Cells were collected after $2 \mathrm{~h}$ expression (a) or treated with rifampicin and labelled with either $\left[{ }^{35} \mathrm{~S}\right]$ methionine and $\left[{ }^{35} \mathrm{~S}\right]$ cysteine $(b)$ or $\left[{ }^{3} \mathrm{H}\right]$ palmitate $(c)$. Proteins were separated by $15 \%$ SDS-PAGE and gels were stained with Coomassie blue (a) or autoradiographed (b, $c)$.

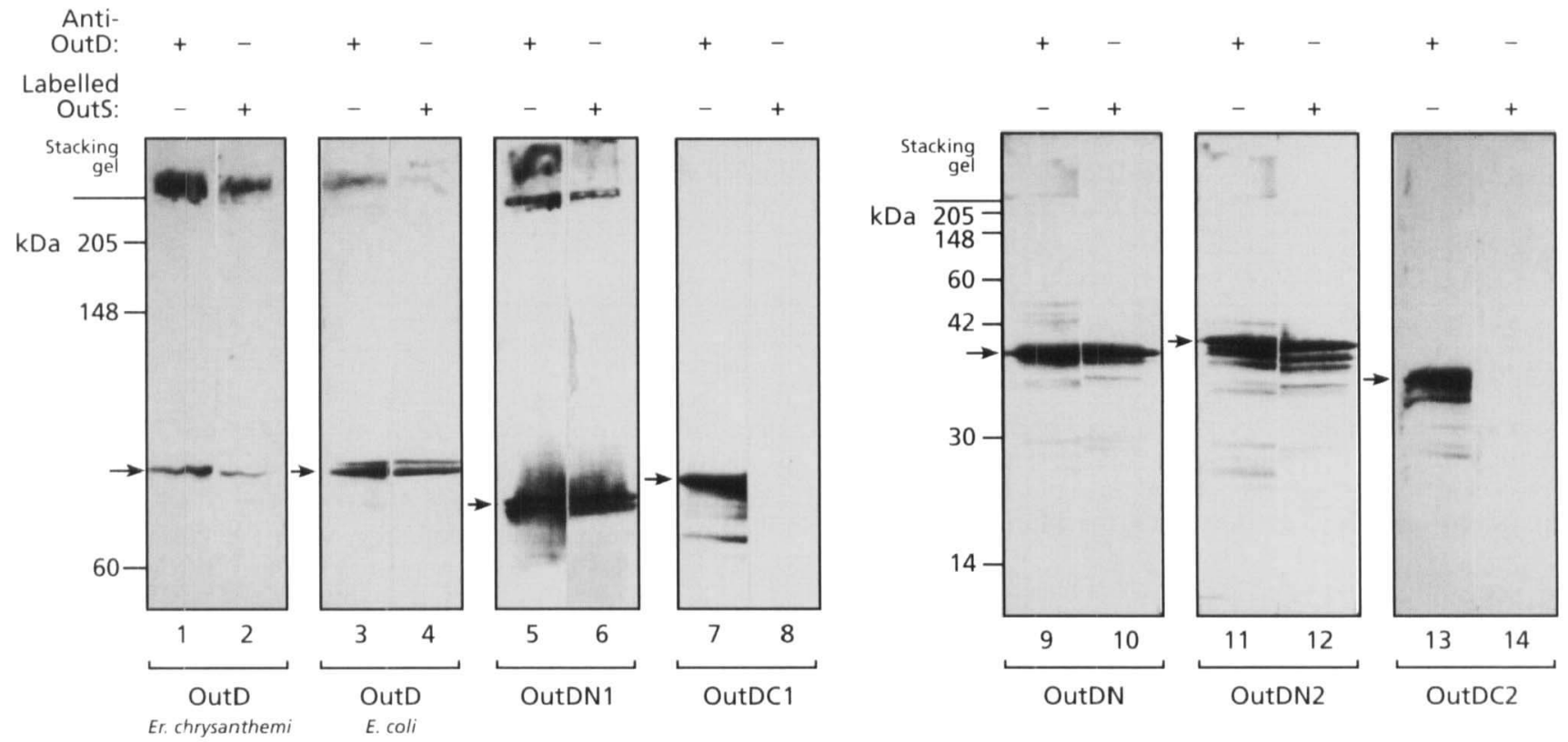

Fig. 3. In vitro interaction of OutS with OutD and OutD derivatives. Proteins from crude membrane fractions of $E r$. chrysanthemi A837/pMMB-OD (lanes 1 and 2), or E. coli BL21 carrying PTdB-OD (lanes 3 and 4), pTdB-ODC1 (lanes 7 and 8), pODN (lanes 9 and 10) or pODN2 (lanes 11 and 12), pTdB-ODC2 (lanes 13 and 14), or E. coli NM522/pODN1 (lanes 5 and 6) were separated by SDS-PAGE and transferred onto a nitrocellulose membrane. The nitrocellulose membrane was incubated either with OutD antibodies (odd-numbered lanes) or with labelled Outs (even-numbered lanes). The arrows indicate the positions of OutD and OutD derivatives. 

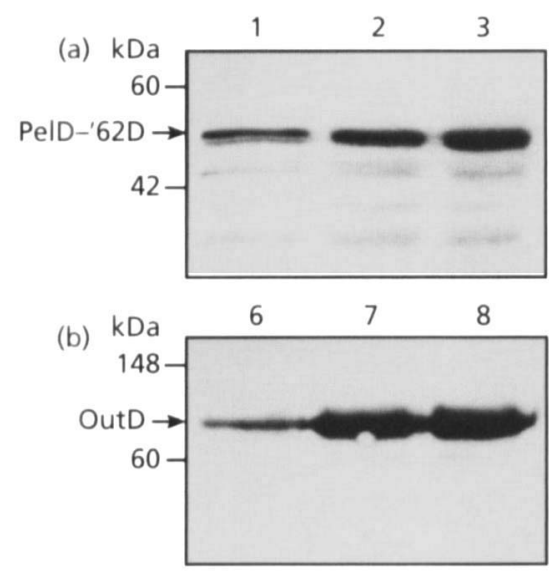

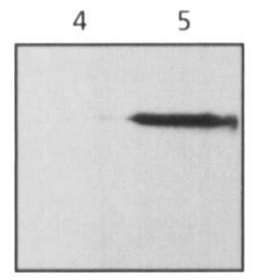

9

(c)

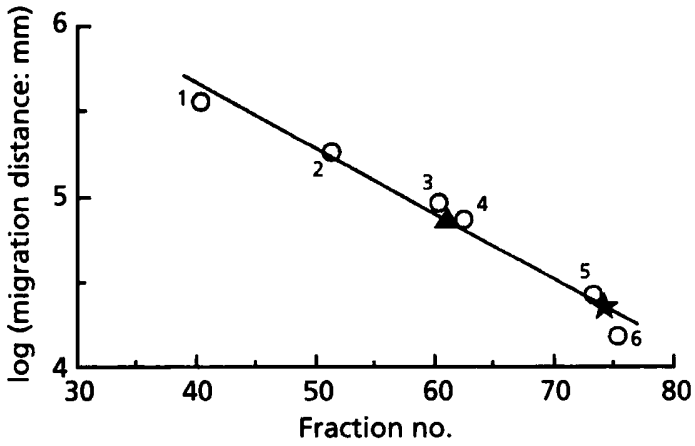

Fig. 4. Effect of OutS and PelB $B^{\text {sp }}$-OutS on the stability and cellular localization of PelD-'62D and OutD. (a) Proteins were separated by SDS-PAGE and analysed by immunoblotting with PelD antibodies: total cell lysates of $E$. coli NM522/pTPLD-'62D/pACT3 (OutS-) (lane 1), NM522/pTPLD-'62D/pACTS1 (PelB ${ }^{\text {sp }-O u t S ~}{ }^{+}$) (lane 2), NM522/pTPLD-'62D/pACOS (OutS') (lane 3) or the periplasmic (lane 4) and the osmotic-shocked cell (lane 5) fractions of NM522/pTPLD-'62D/pACTS1 (PelB sp_OutS $^{+}$). (b) Proteins were separated by SDS-PAGE and analysed by immunoblotting with OutD antibodies: total cell lysates of $E$. coli NM522/pTdB-OD/pACT3 (OutS ${ }^{-}$) (lane 6), NM522/pTdB-OD/pACTS1 $\left(\right.$ PelB $^{\text {sp }}$-OutS ${ }^{+}$) (lane 7), NM522/pTdB-OD/pACOS (OutS ${ }^{+}$(lane 8) or the periplasmic (lane 9) and the osmotic-shocked cell (lane 10) fractions of NM522/pTdB-OD/pACTS1 (PelB ${ }^{\text {sP }}$-OutS ${ }^{+}$) were analysed. (c) Gel-filtration chromatography analysis of the periplasmic proteins of $E$. coli NM522/pTdB-OD/pACTS1 (OutD ${ }^{+}$, PelB sp_-OutS $^{+}$). The OutD (filled triangle) and OutS (filled star) positions are indicated. The column was calibrated with ( 1 and 2 ) $\alpha_{2}$-macroglobulin ( 340 and $170 \mathrm{kDa}-$ nonreduced and reduced forms, respectively), (3) fructose-6-phosphate kinase ( $85 \mathrm{kDa}),(4)$ BSA (67 kDa), (5) chymotrypsinogen A (25 kDa) and (6) RNase A (13.7 kDa).

density gradient allowed for the detection of OutS in the outer-membrane fraction (data not shown). Thus, OutS is an outer-membrane lipoprotein.

\section{Interaction between OutS and OutD requires the last 62 amino acids of OutD}

We have shown that OutD is protected when coexpressed in E. coli with OutS, and that this protection requires the $62 \mathrm{C}$-terminal amino acids of OutD to be present (Shevchik et al., 1997). The protection of OutD by OutS observed in vivo led us to suppose that there is a direct interaction between these two proteins. Ligandblotting experiments were performed to confirm in vitro the potential OutD-OutS interactions. The membrane proteins of the Er. chrysanthemi strain A837/pMMB$\mathrm{OD}$ and of an E. coli strain overproducing OutD were separated by SDS-PAGE and transferred onto a nitrocellulose membrane. When the nitrocellulose membrane was incubated with ${ }^{35} \mathrm{~S}$-labelled OutS, binding of radioactive proteins was observed at a position corresponding to OutD (Fig. 3, lanes 2 and 4). No interaction with any other protein was observed, suggesting that OutD is the only Er. chrysanthemi protein able to interact with OutS. This experiment was then performed with deletion derivatives of OutD, lacking either the N-terminal domain (OutDN, OutDN1 and OutDN2) or the Cterminal domain (OutDC1 and OutDC2). OutS binding was not observed to the OutDC1 and OutDC2 derivatives lacking 62 and 328 amino acids, respectively (Fig. 3, lanes 8 and 14). These results indicate that the in- teraction between OutD and OutS occurs via the Cterminal part of OutD.

To test whether the $62 \mathrm{C}$-terminal amino acids of OutD are sufficient to confer the ability to interact with OutS, a fusion between the secreted protein PelD, deleted of its $12 \mathrm{C}$-terminal amino acids, and the $62 \mathrm{C}$-terminal amino acids of OutD was constructed (pTPLD-'62D). The fusion protein was unstable in E. coli, but was stabilized by the coexpression of OutS (Fig. 4a, lanes 1 and 3). A cell fractionation experiment showed that PelD-'62D was neither extracted by osmotic shock with the periplasmic proteins (Fig. 4a, lanes 4 and 5) nor localized in the outer-membrane fraction, but remained at the bottom of the sucrose gradient (data not shown), probably in aggregated form. Thus, the presence of the 62 C-terminal amino acids of OutD is sufficient to protect the fusion but it is not sufficient to localize it to the outer membrane.

\section{OutS assists in the maturation and stabilization of OutD}

When outD was overexpressed in $E$. coli, resulting in a large proportion of OutD being unprocessed, coexpression of outS significantly increased the amount of mature OutD (Fig. 5). OutS was bound to unprocessed OutD (with its signal sequence) and to the OutD derivative located in the cytoplasm (OutDN) in ligandblotting experiments (Fig. 3, lanes 3, 4, 9 and 10), suggesting that it could bind to the unprocessed OutD 


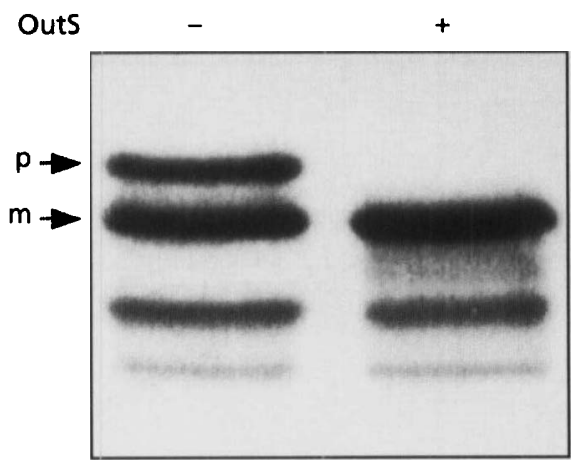

Fig. 5. Outs helps in the maturation of OutD. Crude membrane fractions of $E$. coli $\mathrm{BL} 21 / \mathrm{pTdB}-\mathrm{OD} / \mathrm{pB}$ luescript (OutS ${ }^{-}$) or BL21/pTdB-OD/pBA3 (OutS ${ }^{+}$) were separated by SDS-PAGE and detected with OutD antibodies. The OutD precursor $(p)$ and mature $(m)$ forms are indicated.

precursor in vivo. We have no evidence that OutS can interact with OutD in the cytoplasm, but OutS could interact with the translocation intermediate of OutD from the periplasmic side and help its translocation through the Sec machinery. This effect could explain, in part, the increased quantity of OutD found in strains expressing outS. However, it may result from a protection of OutD by OutS after its translocation through the inner membrane. To confirm that the interaction between OutD and OutS results in an increased stability of mature OutD, pulse-chase experiments were performed. OutD stability was investigated in E. coli $\mathrm{K} 38$, either expressing or not expressing outS. While OutD alone had a half-life of $30 \mathrm{~min}$ in the presence of OutS, no decrease in the quantity of OutD was observed after $1 \mathrm{~h}$ (Fig. 6). Moreover, in the absence of OutS, a significant amount of OutD precursor, present at time 0 , stayed visible during the experiment, confirming the role of OutS in OutD maturation.

\section{Functional analysis of OutS mutant proteins}

To analyse whether protection of OutD by OutS can occur independently from its insertion into the outer membrane, we tried to separate the two functions of OutS (protection of OutD and its insertion into the outer membrane), by constructing or isolating mutants of the protein. The lipoprotein signal sequence of OutS was replaced by the PelB signal sequence to create

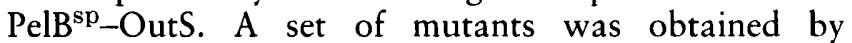
hydroxylamine mutagenesis of the outS gene present on pBA3. After transformation by electroporation of an Er. chrysanthemi OutS ${ }^{-}$mutant, plasmids unable to restore pectinase secretion were screened. The out $S$ gene present on these plasmids was sequenced to identify the mutation. Four nonsense and seven missense mutations were obtained (Fig. 1). The four nonsense mutants gave predicted mature derivatives of 22, 61, 70 and 81 amino acids. The missense mutants are A32T, L37F, R43C, A60T, A60V, S77N and R110C. The PelB ${ }^{\text {sp }_{-} \text {OutS }}$ protein was located in the periplasm, while two mutants, L $32 \mathrm{~F}$ and $\mathrm{R} 110 \mathrm{C}$, were still outer-membrane located (data not shown). The ability of these mutants to stabilize OutD in vivo and to help its insertion in the outer membrane was tested.

The pelB ${ }^{\text {sp }}$-out $S$ construct was unable to complement an Er. chrysanthemi OutS $S^{-}$mutant. Moreover, it inhibited secretion when introduced into the wild-type strain. However, it was able to protect OutD, since coexpression of $p e l B^{\mathrm{Sp}}$-out $S$ with outD led to an increase in the amount of OutD in the cells (Fig. 4 b, lanes 6 and 7). The recombinant protein seemed to stabilize OutD as a periplasmic intermediate: in an $E$. coli strain expressing OutD with PelB ${ }^{\mathrm{sp}}$-OutS, about $50 \%$ of the total OutD could be released by osmotic shock, as were other periplasmic proteins (Fig. 4b, lanes 9 and 10 ). Determination, by centrifugation on a sucrose gradient, of the OutD position in a strain expressing outD with pelB $^{\mathrm{sp}}$-outS showed that, although most of OutD was present in the soluble fraction, part of it could be found (a)

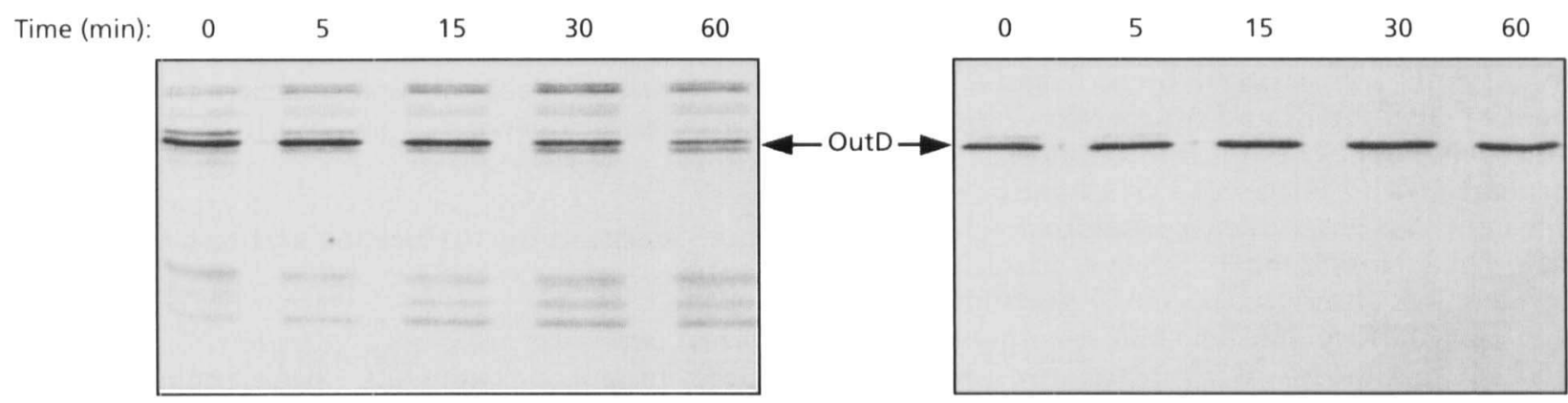

Fig. 6. Post-translational stabilization of OutD by OutS. E. coli K38/pGP1-2/pT7dB-OD/pVLT31 (OutD ${ }^{+}$, OutS O $^{-}$(a) and K38/pGP1-2/pT7dB-OD/pVLTS (OutD ${ }^{+}$, OutS ${ }^{+}$) (b) cells were induced and labelled with [ ${ }^{35} S$ ]methionine and $\left.{ }^{35} S\right]$ cysteine. An excess of unlabelled methionine and cysteine was added 2 min later and the cells were incubated for an additional $60 \mathrm{~min}$. Culture samples were removed during the incubation. Proteins were separated by SDS-PAGE and autoradiographed. 


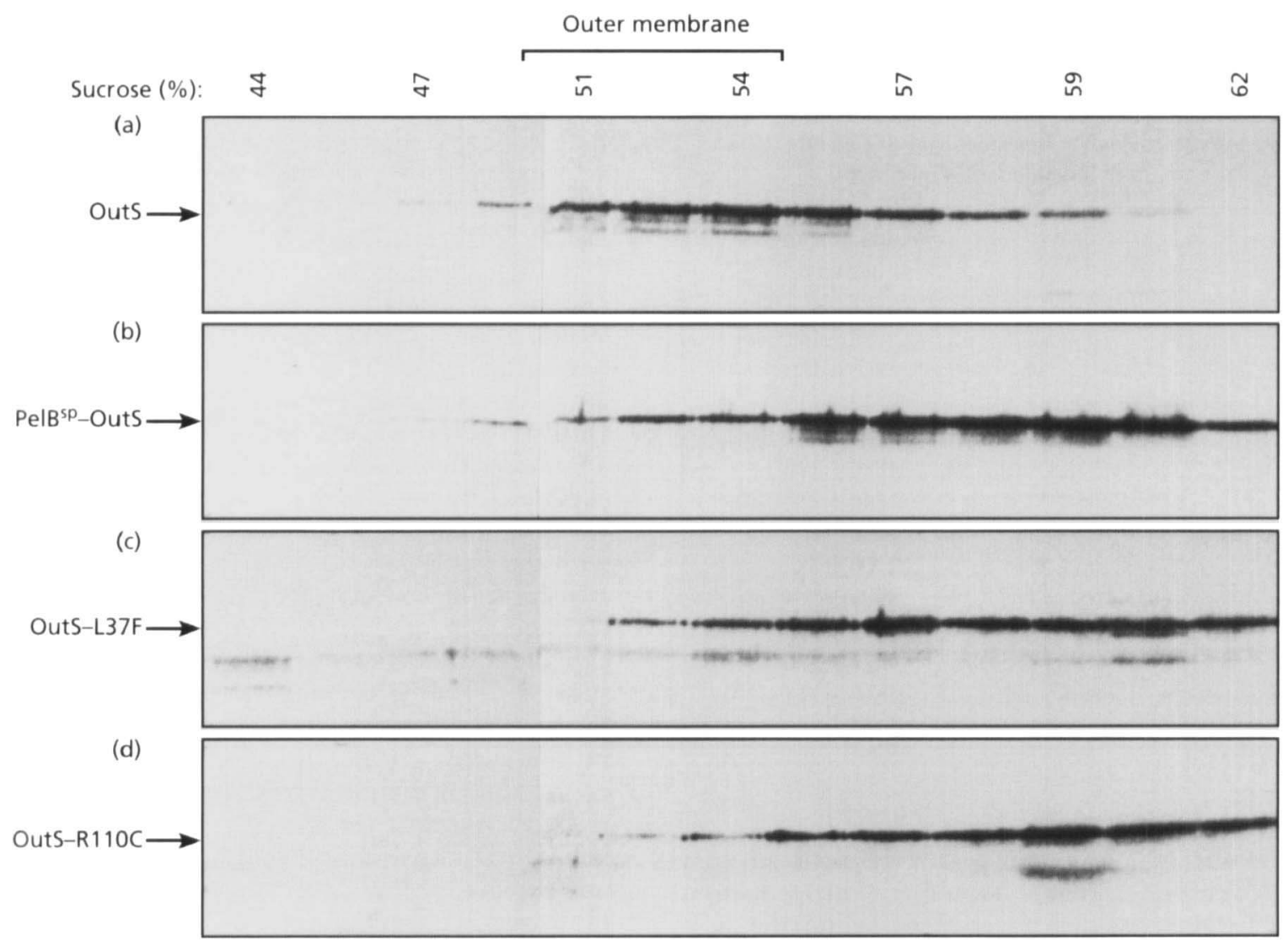

Fig. 7. Mutated OutS proteins are unable to localize OutD to the outer membrane. French press lysates of $E$. coli NM522/pTdB-OD/pACOS (OutD ${ }^{+}$, OutS ${ }^{+}$) (a), NM522/pTdB-OD/pACTS1 (OutD ${ }^{+}$, PelB $^{\text {sp }}-$ OutS $^{+}$) (b), NM522/pACOS/pBA3-37 (OutD + L37F OutS ${ }^{+}$) (c), NM522/pACOS/pBA3-110 (OutD ${ }^{+}$, R110C OutS $^{+}$) (d) were fractionated in a flotation sucrose gradient. Aliquots from each fraction were analysed by SDS-PAGE and immunoblotting with OutD antibodies.

in the outer-membrane fraction [Fig. 7 (b)]. We have observed previously (Shevchik et al., 1997) that a small amount of OutD can insert into the outer membrane, even in the absence of OutS. Thus, the presence of OutD in the outer membrane may not result from the presence of PelB ${ }^{\text {sp}}$-OutS. Ligand-blotting experiments showed that PelB ${ }^{\text {sp }}$-OutS is able to interact in vitro with OutD, although with a lower affinity than OutS (data not shown). To determine whether the periplasmic OutD (in the presence of PelB ${ }^{\mathrm{sp}}$-OutS) is multimeric, we performed gel-filtration analysis of the periplasmic fraction of $E$. coli strain NM522/pTdB-OD/pACTS1. OutD was eluted only at a retention time close to that of fructose-6-phosphate kinase $(85 \mathrm{kDa})$ and of BSA $(67 \mathrm{kDa})$ (Fig. 4c). This result indicates that OutD stays monomeric in the periplasmic fraction. Surprisingly, no OutS was detected in the OutD fractions. This protein was completely eluted in low-molecular-mass protein fractions (about $10-15 \mathrm{kDa}$ ) (Fig. 4c). The

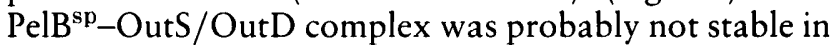
the periplasm or was dissociated during the gel filtration.

None of the nonsense mutants were able to protect or to help insertion of OutD into the outer membrane. Contrarily, in vivo and in vitro experiments showed that all the missense mutants were able to protect and to bind
OutD like the wild-type OutS (data not shown). However, despite their outer-membrane location, none of them was able to help OutD insertion in the outer membrane (shown for mutants L37F and R110C in Fig. $7 \mathrm{c}$ and $\mathrm{d}$ ). Thus, only missense mutants affected in the pilotin function have been isolated.

\section{Induction of pspA by OutD in the presence of OutS mutants}

Expression of the phage shock protein PspA is induced by overexpression of outer-membrane proteins. Among them, protein IV of filamentous phages and its homologues, the GspD proteins, are very good inducers. It has been proposed that the process of insertion of these proteins into the outer membrane, or Sec machinery jamming, could trigger $p s p A$ induction (Model et al., 1997). Induction of $p s p A$ by PulD can be prevented by the presence of PulS, indicating that although the quantity of PulD increases, its insertion is improved (Hardie et al., 1996a). Overexpression of OutD in E. coli also induced $p s p A$ expression, measured by the assay of a $p s p A-l a c Z$ fusion (Table 2). The effect of outS and its mutant derivatives was tested. Coexpression of OutS with OutD reduced $p s p A$ induction (Table 2), although 
Table 2. Induction of a pspA-lacZ fusion by OutD in the presence of different GspS proteins

Strain MC3 was grown in LB medium. The results reported [as nmol product liberated $\min ^{-1}(\mathrm{mg} \text { bacterial dry weight })^{-1}$ ] are the mean of at least three independent experiments.

\begin{tabular}{|ccc|}
\hline OutD & GspS & $\begin{array}{c}\boldsymbol{\beta} \text {-Galactosidase } \\
\text { activity }\end{array}$ \\
\hline- & - & $98 \pm 14$ \\
+ & - & $1970 \pm 130$ \\
+ & OutS & $510 \pm 113$ \\
+ & PulS & $157 \pm 26$ \\
+ & PelB ${ }^{\text {sp_OutS }}$ & $1880 \pm 120$ \\
+ & OutS A32T & $1640 \pm 237$ \\
+ & OutS L37F & $6030 \pm 605$ \\
+ & OutS R43C & $2700 \pm 187$ \\
+ & OutS A60V & $3090 \pm 573$ \\
+ & OutS A60T & $4200 \pm 640$ \\
+ & OutS S77N & $4670 \pm 370$ \\
+ & OutS R110C & $1600 \pm 315$ \\
+ & OutS81 & $2160 \pm 223$ \\
\hline
\end{tabular}

less than PulS, which is able to complement an outS mutant (data not shown). However, the reduction observed varied considerably, depending on the stoichiometry of the two GspS and GspD proteins. When $\mathrm{PelB}^{\mathrm{sp}}$-OutS or the OutS point mutants were coexpressed with OutD, not only was no decrease in the expression of the fusion observed, but in some cases, an increase was noted (Table 2). This may result from the reduced efficiency of these mutants to assist in the release of OurD from the inner membrane, or from the increased amount of stabilized, but incorrectly localized, OutD.

\section{DISCUSSION}

To reach their final cellular location, outer-membrane proteins have to travel across the periplasm prior to their correct incorporation into the outer membrane. Recent studies suggest that, for some proteins, these processes require specific chaperones that help them cross the periplasmic space and/or insert into the membrane. The Skp protein facilitates the insertion of OmpA, OmpC, OmpF and LamB in the outer membrane and forms complexes with these proteins during translocation across the periplasm (Chen \& Henning, 1996; Missiakas et al., 1997). p20 is a periplasmic protein that carries the lipoprotein Lpp from the inner membrane to the outer membrane (Matsuyama et al., 1995). The outer-membrane components of the GSP called secretins, seem to require specific lipoproteins to direct them to the outer membrane: in Pseudomonas syringae and Neisseria gonorrboeae, PilP is required for the insertion of PilQ (Roine et al., 1996; Drake et al., 1997). The VirG lipoprotein is required for efficient targeting of YscC to the outer membrane (Koster et al., 1997). The chaperone-like role of PulS has been well documented (Hardie et al., 1996a, b; Daefler et al., 1997).

We show here that the lipoprotein OutS is a specific chaperone that interacts with OutD to stabilize it and to help its insertion into the outer membrane. The protection effect of OutS is due to the direct interaction of the two proteins. Ligand-blotting experiments showed that interaction between OutD and OutS does not require additional proteins. While only the $62 \mathrm{C}$ terminal amino acids of OutD are necessary for the interaction to occur, no region of OutS specific for this interaction has been found. The observation that when OutD is overproduced, coexpression with OutS strongly diminishes the quantity of unmaturated OutD could be explained by intervention of OutS in the OutD translocation. OutS could interact from the periplasmic side with the OutD translocation intermediate and help its translocation through the Sec machinery. The slow translocation of OutD in the absence of OutS could explain the induction of $p s p A$. Kleerebezem et al. (1996) suggested that the accumulation of protein precursors in the Sec machinery could lead to the dissipation of the proton-motive force. This would in turn induce $p s p A$ expression. A diminution of the efficiency of the OutS missense mutants and the periplasmic form of OutS to help OutD translocation could confirm this hypothesis and explain the high level of $p s p A$ expression observed. However, we were unable to obtain strong data supporting this hypothesis. No difference in the OutD precursor maturation efficiency was detected in the presence of the OutS missense mutants and the periplasmic form of OutS (data not shown).

The presence of a lipoprotein-type signal sequence is necessary for the pilotin function of OutS toward OutD. Its replacement by a type I peptide signal localizes OutD in the periplasm. However, the localization of OutS in the outer membrane does not determine the destination of the protein with which it interacts. Although PelD-'62D interacts with, and is stabilized by, OutS, it is not localized in the outer membrane. Thus, it seems likely that it is the intrinsic properties of OutD that confer on it the outer-membrane location. On the other hand, the function of OutS might not be to insert OutD into the outer membrane, but to draw it into contact with this membrane so that its insertion is facilitated. The partial presence in the outer membrane of OutD, or its truncated derivative OutDC1 (which lacks the 62 Cterminal amino acids and thus is incapable of interacting with OutS), in the absence of OutS, confirms that this insertion can occur spontaneously, albeit with low efficiency (Shevchik et al., 1997). However, there are no data to indicate that spontaneously inserted OutD is in a functional state. A spontaneous insertion of a PulD-PhoA hybrid, containing the $\mathrm{N}$-terminal region of PulD, into the outer membrane has also been observed (Hardie et al., 1996a).

Analysis of OutS mutants showed that the two functions of OutS can be separated: protection of OutD and assistance of its insertion into the outer membrane. All 
the non-functional outS point mutants isolated conserve their protection function, but are unable to localize OutD to the outer membrane. During the screening, we retained only mutants that gave less than $5 \%$ of the wild-type level of secretion. In doing this, we have excluded mutations giving a less stringent phenotype. Interestingly, the mutated amino acids are all conserved in OutS and PulS (Fig. 1). Conservation of these residues in two proteins that show only $40 \%$ identity suggests that they might play a direct role in the pilotin function of these proteins. The lack of mutants with an altered protection function suggests that mutation of a single amino acid is not sufficient to abolish OutS-OutD interaction. The four out $S$ nonsense mutations obtained gave unstable truncated proteins and were of no use in testing the effect of shorter proteins on OutD. It would be interesting to look for other types of OutS mutants (in-frame deletions, insertions, hybrids) that are unable to interact with OutD, to identify the basis of this interaction. There is no obvious reason for the pilotindeficient phenotype of the outS missense mutants. The lipoprotein sequence signal and the second amino acid after the cleavage site, which is important for the final membrane localization of lipoproteins (Yamaguchi et al., 1988), were not modified. Moreover, at least two of the OutS missense mutants, R110C and L37F, have been shown to be outer-membrane located in both E. coli and Er. chrysanthemi (data not shown). The fact that the protection of OutD by the OutS mutants is efficient, but that OutD insertion in the outer membrane does not occur normally led us to suppose that these mutations prevent one of the last steps of the process of insertion/ multimerization of OutD in the outer membrane. OutD multimerization does not occur when it is located in the periplasm in the presence of PelB ${ }^{\mathrm{sp}}$-OutS. Thus, the mutations might have modified the conformation of OutS and its ability to draw OutD into contact with the outer membrane or the binding capacity of the OutD-OutS complex to an hypothetical outermembrane receptor and/or prevented the ability of OutD to form stable multimers.

\section{ACKNOWLEDGEMENTS}

We thank A. Pugsley for anti-OutS antibodies and pCHAP378, Dr F. Turnowsky for providing a $p s p A-l a c Z$ strain, and $\mathrm{N}$. Cotte-Pattat, S. Reverchon, W. Nasser and V. James for reading the manuscript. This work was supported by grants from the Fondation pour la Recherche Médicale, the CNRS and the DRED.

\section{REFERENCES}

Bergler, H., Abraham, D., Aschauer, H. \& Turnowsky, F. (1994). Inhibition of lipid biosynthesis induces the expression of the $p s p A$ gene. Microbiology 140, 1937-1944.

Brissette, J. L. \& Russel, M. (1990). Secretion and membrane integration of a filamentous phage-encoded morphogenetic protein. J Mol Biol 211, 565-580.

Chen, R. \& Henning, U. (1996). A periplasmic protein (Skp) of Escherichia coli selectively binds a class of outer membrane proteins. Mol Microbiol 19, 1287-1294.
Chen, L.-Y., Chen, D.-Y., Miaw, J. \& Hu, N.-T. (1996). XcpD, an outer membrane protein required for protein secretion by Xanthomonas campestris pv. campestris, forms a multimer. J Mol Biol 271, 2703-2708.

Condemine, G., Dorel, C., Hugouvieux-Cotte-Pattat, N. \& RobertBaudouy, J. (1992). Some of the out genes involved in the secretion of pectate lyases in Erwinia chrysanthemi are regulated by $k d g R$. Mol Microbiol 6, 3199-3211.

Daefler, S., Guilvout, I., Hardie, K. R., Pugsley, A. P. \& Russel, M. (1997a). The C-terminal domain of the secretin PulD contains the binding site for its cognate chaperone, PulS, and confers PulS dependence on pIV ${ }^{n 1}$ function. Mol Microbiol 24, 465-475.

Daefler, S., Russel, M. \& Model, P. (1997b). Module swaps between related translocator proteins $\mathrm{pIV}^{\mathrm{f1}}$, pIV ${ }^{\mathrm{lke}}$ and PulD: identification of a specificity domain. $J$ Mol Biol 266, 978-992.

Drake, S. L. \& Koomey, M. (1995). The product of the pilQ gene is essential for the biogenesis of the type IV pili in Neisseria gonorrhoeae. Mol Microbiol 18, 975-986.

Drake, S. L., Sandstedt, S. A. \& Koomey, M. (1997). PilP, a pilus biogenesis lipoprotein in Neisseria gonorrhoeae, affects expression of PilQ as a high-molecular-mass multimer. $\mathrm{Mol}$ Microbiol 23, 657-668.

Dykxhoorn, D. M., St Pierre, R. \& Furlong, C. E. (1996). A set of compatible tac promoter expression vectors. Gene 177, 133-136.

d'Enfert, C. \& Pugsley, A. P. (1987). Klebsiella pneumoniae pulS gene encodes an outer membrane lipoprotein required for pullulanase secretion. J Bacteriol 171, 3673-3679.

Genin, S. \& Boucher, C. A. (1994). A superfamily of proteins involved in different secretion pathways in Gram-negative bacteria : modular structure and specificity of the $\mathrm{N}$-terminal domain. Mol Gen Genet 243, 112-118.

Hardie, K. R., Lory, S. \& Pugsley, A. P. (1996a). Insertion of an outer membrane protein in Escherichia coli requires a chaperonelike protein. EMBO J 15, 978-988.

Hardie, K. R., Seydel, A., Guilvout, I. \& Pugsley, A. P. (1996b). The secretin-specific, chaperone-like protein of the general secretory pathway: separation of proteolytic protection and piloting functions. Mol Microbiol 22, 967-976.

Hugouvieux-Cotte-Pattat, N., Dominguez, H. \& Robert-Baudouy, J. (1992). Environmental conditions affect transcription of the pectinase genes of Erwinia chrysanthemi 3937. J Bacteriol 174, 7807-7818.

Johnson, B. H. \& Hecht, M. H. (1994). Recombinant proteins can be isolated from $E$. coli cells by repeated cycles of freezing and thawing. Bio/Technology 12, 1357-1360.

Kleerebezem, M., Crielaard, W. \& Tommassen, J. (1996). Involvement of stress protein PspA (phage shock protein A) of Escherichia coli in maintenance of the proton motive force under stress conditions. EMBO J 15, 162-171.

Koster, M., Bitter, W., de Cock, H., Allaoui, A., Cornelis, G. R. \& Tommassen, J. (1997). The outer membrane component, YscC, of the Yop secretion machinery of Yersinia enterocolitica forms a ring-shaped multimeric complex. Mol Microbiol 26, 789-797.

Laemmli, U. K. (1970). Cleavage of structural proteins during the assembly of the head of bacteriophage T4. Nature 227, 680-685.

Linderoth, N. A., Simon, M. A. \& Russel, M. (1997). The filamentous phage pIV multimer visualized by scanning transmission electon microscopy. Science 278, 1635-1638.

de Lorenzo, V., Eltis, L., Kessler, B. \& Timmis, K. N. (1993). Analysis of Pseudomonas gene products using $\operatorname{lacl}^{q} / \mathrm{Ptrp}-\mathrm{lac}$ plasmids and transposons that confer conditional phenotypes. Gene 123, 17-24. 
Matsuyama, S.-I., Tajima, T. \& Tokuda, H. (1995). A novel periplasmic carrier protein involved in the sorting and transport of Escherichia coli lipoproteins destined for the outer membrane. EMBO J 14, 3365-3372.

Miller, J. H. (1972). Experiments in Molecular Genetics. Cold Spring Harbor, NY: Cold Spring Harbor Laboratory.

Missiakas, D., Betton, J.-M. \& Raina, S. (1997). New components of protein folding in extracytoplasmic compartments of Escherichia coli SurA, FkpA, and Skp/OmpH. Mol Microbiol 21, 871-884.

Model, P., Jovanovic, G. \& Dworkin, J. (1997). The Escherichia coli phage-shock-protein (psp) operon. Mol Microbiol 24, 255-261.

Moran, F., Nasuno, S. \& Starr, M. P. (1968). Extracellular and intracellular polygalacturonic transeliminases of Erwinia carotovora. Arch Biochem Biophys 123, 298-306.

Noonan, B. \& Trust, T. J. (1995). Molecular analysis of an Aprotein secretion mutant of Aeromonas salmonicida reveals a surface layer-specific protein secretion pathway. J Mol Biol 248, 316-327.

Roine, E., Nunn, D. N., Paulin, L. \& Romantschuk, M. (1996). Characterization of genes required for pilus expression in Pseudomonas syringae pathovar phaseolicola. J Bacteriol 178, 410-417.

Russel, M. \& Kazmierczak, B. (1993). Analysis of the structure of the subcellular location of filamentous phage pIV. J Bacteriol 175, 3998-4007.
Russel, M. \& Model., P. (1984). Replacement of the fip gene of Escherichia coli by an inactive gene cloned on a plasmid. J Bacteriol 159, 1034-1039.

Sambrook, J., Fritsch, E. F. \& Maniatis, T. (1989). Molecular Cloning: a Laboratory Manual, 2nd edn. Cold Spring Harbor, NY: Cold Spring Harbor Laboratory.

Shevchik, V. E., Condemine, G., Hugouvieux-Cotte-Pattat, N. \& Robert-Baudouy, J. (1996). Characterization of pectin methylesterase B, an outer membrane lipoprotein of Erwinia chrysanthemi 3937. Mol Microbiol 19, 455-466.

Shevchik, V. E., Robert-Baudouy, J. \& Condemine, G. (1997). Specific interaction between OutD, an Erwinia chrysanthemi outer membrane protein of the general secretory pathway, and secreted proteins. EMBO J 16, 3007-3016.

Tabor, S. \& Richardson, C. (1985). A bacteriophage T7 RNA polymerase/promoter system for controlled exclusive expression of specific genes. Proc Natl Acad Sci USA 82, 1074-1078.

Yamaguchi, K., Yu, F. \& Inouye, M. (1988). A single amino acid determinant of the membrane localization of lipoproteins in E. coli. Cell 53, 423-432.

Yang, J., Ganesan, S., Sarsero, J. \& Pittard, A. J. (1993). A genetic analysis of various functions of the TyrR protein of Escherichia coli. J Bacteriol 175, 1767-1776.

Received 25 June 1998; accepted 27 July 1998. 